\title{
Application of an improved method for measurements of gaseous nitric acid in the nonurban atmosphere
}

\begin{abstract}
K. P. Müller and J. Rudolph
Summary. A modified filter technique to separate particles and gaseous $\mathrm{HNO}_{3}$ is described, which is based on the use of filters of the Millipore FPLG type in combination with a virtual impactor. It enables routine measurements of gaseous $\mathrm{HNO}_{3}$ in the atmosphere at background levels. Some results of measurements both in the marine background and over rural and semi-rural continental regions are presented.
\end{abstract}

Institut für Atmosphärische Chemie, Forschungszentrum Jülich GmbH, Postfach 1913, W-5170 Jülich, Federal Republic of Germany

\section{Introduction}

The major final oxidation product of NOx is nitric acid. Incorporation in aerosols and fog, cloud and rain droplets as well as dry deposition are the dominant sink mechanisms for $\mathrm{HNO}_{3}$. Therefore nitric acid can contribute to the acidity in aerosols, cloud droplets and rain. In the remote atmosphere the mixing ratios of $\mathrm{HNO}_{3}$ often are only around some ten pptv to a fraction of one ppbv. In general tropospheric air also contains a substantial excess (in general a factor 3-10) of nitrate on aerosol particles [1, 2]. There exists a substantial number of measuring techniques for $\mathrm{HNO}_{3}$ in the atmosphere. They range from tunable diode lasers [3] and laser-photolysis fragment-fluorescence [4] to simpler, classical techniques such as denuders $[5,6]$ and filter packages with nylon filters $[1,2,7]$. Most measurements in the troposphere are made using nylon filters combined with a Teflon prefilter and subsequent classical wet chemical analysis in the laboratory. This technique is inexpensive and relatively easy to use for routine measurements. On the other hand, sampling of gaseous $\mathrm{HNO}_{3}$ on filter packages may be affected by nitric acid loss or formation processes due to chemical reactions on the prefilter. In this paper a modified filter technique is described which enables routine measurements of gaseous $\mathrm{HNO}_{3}$ in the atmosphere at background levels. Some results from measurements both in the marine background and over rural and semi-rural continental regions are presented.

\section{Experimental}

The sampling technique is similar to a procedure described previously $[2,7,8]$ but has been modified to improve the detection limit and to reduce interferences from aerosols. A schematic drawing of the sampling system is shown in Fig. 1. Gaseous nitric acid was collected by pumping air (100 I $\mathrm{STP} / \mathrm{min}$ ) through a filter stack (Fig. 2) which consists of a

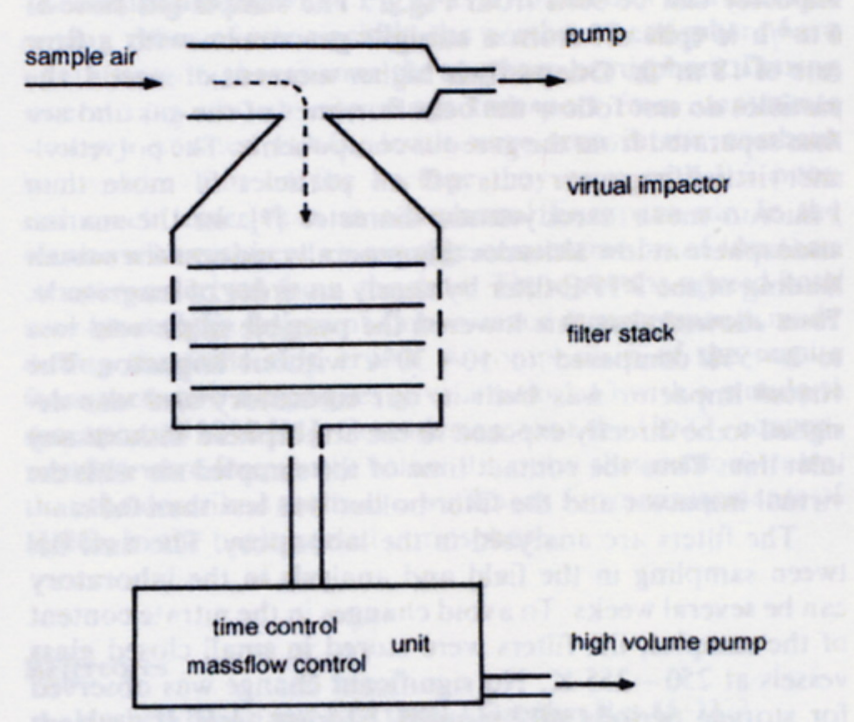

Fig. 1. Schematic drawing of $\mathrm{HNO}_{3}$ sampling system

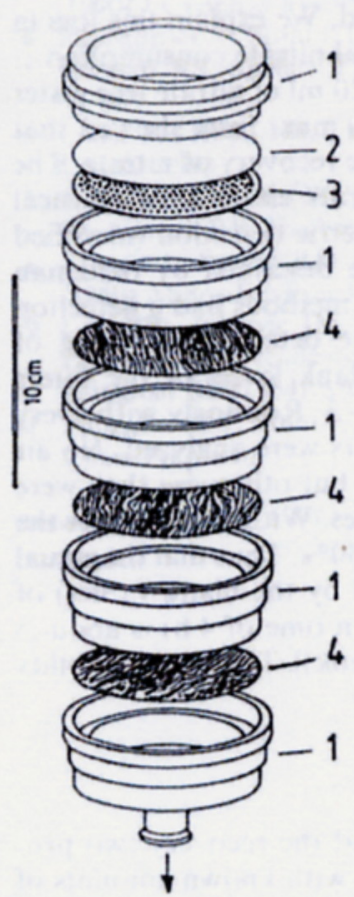

Fig. 2. Diagram of filter stack. 1: distance rings, 2: PTFE filter 3: PTFE coated filter support 4 : nylon filters 
PTFE filter (Millipore FGLP) with a nominal pore size of 0.2 micron followed by three nylon filters. The PTFE filter is needed to remove the particulate nitrate, the nylon filters absorb gaseous $\mathrm{HNO}_{3}$. The preparation of the nylon filters is modified. The filters are thoroughly washed with an aqueous solution of sulfanilamide $(0.1 \%)$ and dried without any further treatment. This resulted in low and very reproducible blank values (see below) and simplified the extraction of the filters. The serial filter scheme allows the routine check of the $\mathrm{HNO}_{3}$ sampling efficiency.

To reduce the negative interference caused by the reaction of sea-salt aerosols collected on the PTFE-filter with $\mathrm{HNO}_{3}$ (sce below) a virtual impactor was installed in front of the filter system. The principle of operation of a virtual impactor can be seen from Fig. 1. The sample gas flow of $6 \mathrm{~m}^{3} / \mathrm{h}$ is split off from a straight gas stream with a flow rate of $18 \mathrm{~m}^{3} / \mathrm{h}$. Due to their higher moment of inertia, the particles do not follow the bent flowlines of the gas and are thus separated from the gaseous components. The polyethylene virtual impactor cuts off all particles of more than 1 micron mean aerodynamic diameter [9]. In the marine atmosphere at low altitudes this generally reduces the seasalt loading of the PTFE filter by nearly an order of magnitude. Tests showed that this lowered the possible nitric acid loss to $2-5 \%$ compared to $10-30 \%$ without impactor. The virtual impactor was built in our laboratory and was designed to be directly exposed to the atmosphere without any inlet line. Thus the contact time of the sampled air with the virtual impactor and the filter holder was less than $0.1 \mathrm{~s}$.

The filters are analyzed in the laboratory. The time between sampling in the field and analysis in the laboratory can be several weeks. To avoid changes in the nitrate content of the samples, the filters were stored in small closed glass vessels at $250-255 \mathrm{~K}$. No significant change was observed for storage periods of 3 months. Storage tests at ambient temperature showed substantial nitrate losses within a few weeks. The loss rates varied and occassionally complete loss of nitrate within 2 weeks was found. We explain this loss in the unsterilized samples by bacterial nitrate consumption.

The filters were extracted with $20 \mathrm{ml}$ of nitrate free water in an ultrasonic bath for about 20 min. Tests showed that this procedure allowed quantitative recovery of nitrate. The liquid phase was analyzed for nitrate either by a classical wet chemical method and photometric detection (modified Griess reaction similar to the one described by Saltzman [10]) or ion chromatography. Both methods had a detection limit of $2 \mathrm{ng} / \mathrm{ml}$. This allowed the detection of $40 \mathrm{ng}$ of nitrate per filter. However, the blank levels of the filters exceed this value by a factor of $2-3$. Routinely with every $\mathrm{HNO}_{3}$ measuring series blank filters were analyzed. No air was pumped through these filters, but otherwise they wcre handled the same way as the samples. Within each series the blanks varied typically by less than $30 \%$. Thus that the actual overall detection limit (determined by the blank values) of the filters in $24 \mathrm{~m}^{3}$ of air (collection lime of $4 \mathrm{~h}$ ) is about 5 pptv of $\mathrm{HNO}_{3}$ [blank plus $3 \sigma$ of blank)]. The reproducibility of the method is better than $10 \%$.

\section{Efficiency and interferences}

To test the collection efficiency and the recovery two procedures for loading the filter packs with known amounts of $\mathrm{HNO}_{3}$ were applied. The first used the evaporation of a known amount of liquid $\mathrm{HNO}_{3}$ in a constant gas stream.
The second was a dynamic gas dilution system combined with a $\mathrm{HNO}_{3}$ permeation source designed and built by $\mathrm{ECN}$ at Petten/NL. The applied $\mathrm{HNO}_{3}$ concentrations were comparable to ambient levels.

The total recovery of $\mathrm{HNO}_{3}$ was better than $98 \%$ and more than $95 \%$ were collected on the first of the nylon filters. Several atmospheric constituents were tested for possible interferences. Gas mixtures containing between several ppbv and 10 ppinv of $\mathrm{N}_{2} \mathrm{O}, \mathrm{NO}_{2}, \mathrm{NH}_{3}, \mathrm{SO}_{2}$ and $\mathrm{PAN}$ were passed through the filter system with flow rates and sampling periods similar to ambient air analyses. The relative humidity could be varied between 5 and $98 \%$. No significant loss of $\mathrm{HNO}_{3}$ or formation of $\mathrm{HNO}_{3}$ artifacts was observed.

Also the possible influences of aerosols collected on the PTFE filter were checked. Ten PTFE filters were loaded with continental aerosols and another ten with marine aerosols. The amount of the test aerosols corresponded to a $24 \mathrm{~h}$ sampling time, this means is 4 to 6 times the volume usually sampled under background conditions. For continental aerosols no changes could be seen, but for seasalt aerosol a 10 to $30 \%$ reduction in the $\mathrm{HNO}_{3}$ content of a test gas passed through the filter was found. The installation of a virtual impactor in front of the filter package reduced this interference by roughly an order of magnitude (see above). The remaining losses of $2-5 \%$ are acceptable within the overall accuracy of the method.

We have made no tests with filters loaded with artificial mixtures of ammoniumnitrate, but several tests with filters loaded with continental aerosols (up to $500 \mu \mathrm{g}$ of nitrate per filter) were made. For Millipore FGLP filters no detectable enhancement of the $\mathrm{HNO}_{3}$ concentration in test gases passed through these filters were found, even if the test gases were loaded with additional sulfuric acid acrosols (up to $130 \mu \mathrm{g}$ per filter). Less favourable results were found if aerosol loaded Nucleopore filters were tested. In this case significantly enhanced $\mathrm{HNO}_{3}$ concentrations were observed. This different behaviour is most probably caused by the different pore structures of the two filter types. Electron microscope images from particle loaded filters indeed showed very different results. For Millipore filters a uniform coverage with generally isolated particles was seen, whereas Nucleopore filters showed small islands of very dense particle coverage.

These test results indicate, that for moderate and low pollution levels the use of filters of the Millipore FPLG type in combination with a virtual impactor to separate particles and gaseous $\mathrm{HNO}_{3}$ is adequate for the marine atmosphere and continental regions of low and moderate pollution levels. However, we have no experience for regions of high pollution levels where high loading of the particle filter may occur in spite of the virtual impactor.

\section{Results}

A detailed presentation and discussion of the results obtained with this method is beyond the scope of this paper. To demonstrate the applicability of the procedure both for measurements in the remote background atmosphere and for routine monitoring in continental areas two examples of extensive measurement series are presented. In a remotc rural area near Jülich/FRG time series measurements of $\mathrm{HNO}_{3}$ were performed during the years 1982 to 1984. Samples were collected twice a day. Day-time measurement were made between 10:00 and 16:00 CET, the night-tim 


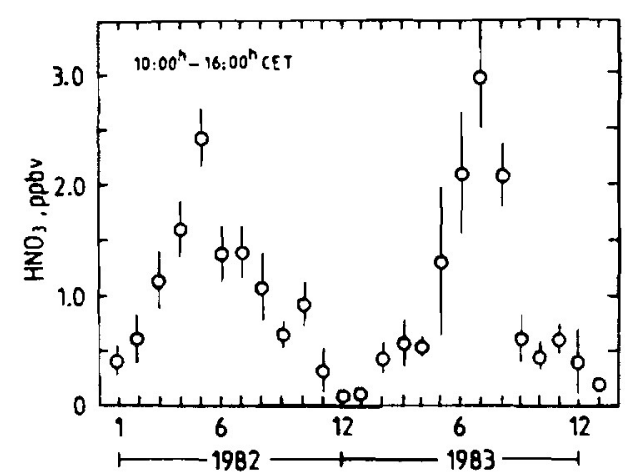

Fig. 3. Monthly means of $\mathrm{HNO}_{3}$ mixing ratios, day-time measurements

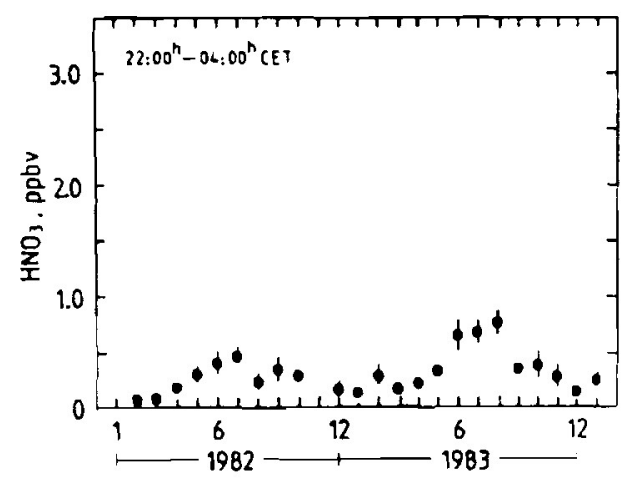

Fig. 4. Monthly means of $\mathrm{HNO}_{3}$ mixing ratios, night-time measurements

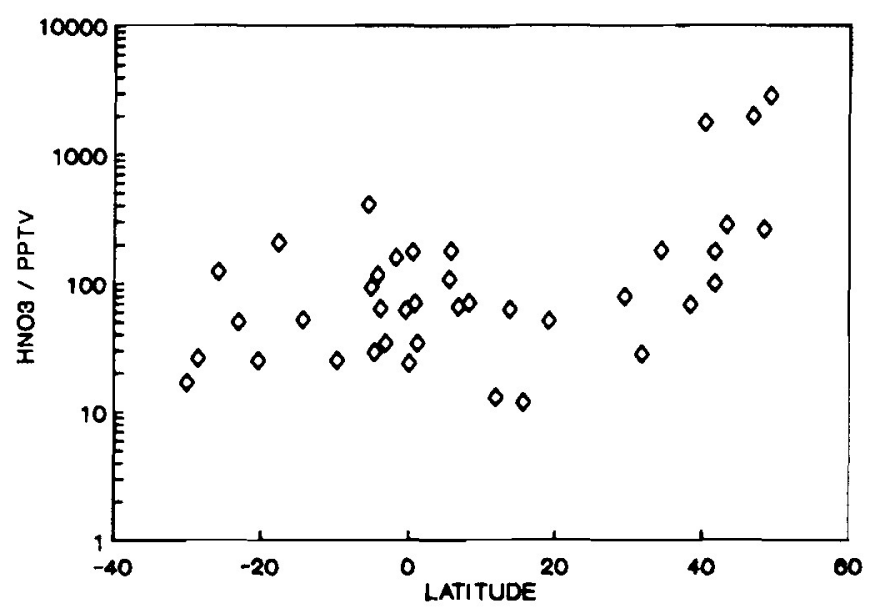

Fig. 5. $\mathrm{HNO}_{3}$ mixing ratios measured during a ship cruise over the Atlantic in September/October 1988 (Polarstern cruise ANT VII/1) measurements between 22:00 and 4:00 CET. The monthly means of the $\mathrm{HNO}_{3}$ mixing ratios are shown in Fig. 3 and Fig. 4 separately for day- and night-time measurements. Each of the points represents the mean of the 20 to 25 datapoints. The day-time measurements show a significant annual variation with mixing ratios exceeding $2 \mathrm{ppbv}$ of $\mathrm{HNO}_{3}$ during summertime and less than $0.5 \mathrm{ppbv}$ in winter. The night-time data show a qualitatively similar picture but the $\mathrm{HNO}_{3}$ mixing ratios are on the average by a factor of 5 lower.

Another data set from an area with much lower $\mathrm{HNO}_{3}$ mixing ratios was obtained during the cruise ANT VII/1 of RV "POLARSTERN" over the Atlantic from Bremerhaven/ FRG to Rio Grande/Brazil (from about $50^{\circ} \mathrm{N}$ to $30^{\circ} \mathrm{S}$ ). The results are shown in Fig. 5 as a function of latitude. The mixing ratios of nitric acid in the northern hemisphere were significantly higher than in the southern hemisphere. During several episodes of long range transport from continents strongly elevated $\mathrm{HNO}_{3}$ levels were seen in the northern hemisphere. But on the average they were with $0.2 \mathrm{ppbv}$ still much lower than in continental European air. In the southern hemisphere an average concentration of less than $30 \mathrm{pptv}$ is derived from the data. These results agreed with laser-photolysis fragment-fluorescence measurements made during the same ship cruise. A comparison of the results from these two techniques gave a ratio 1.13 with a standard deviation of $28 \%$ [11]. Considering, that the $\mathrm{HNO}_{3}$ concentrations were frequently below 0.1 ppbv this demonstrates, that the described method is sufficient for measurements of $\mathrm{HNO}_{3}$ in the background atmosphere.

\section{References}

1. Huebert BJ, Lazrus AL (1980) J Geophys Res 85: 7322

2. Huebert BJ (1980) Geophys Res Lett 7:325

3. Schiff HI, Karecki DR, Harris GW, Hastie DR, Mackay GI (1990) J Geophys Res 95:10147

4. Papenbrock T, Stuhl F (1990) J Atmos Chem 10:451

5. Braman RS, Shelley TJ, McClenny WA (1982) Anal Chem $54: 358$

6. LeBel PJ, Hoell JM, Levine JS, Vay SA (1985) Geophys Res Lett 12:1995

7. Goldan PD, Custer WC, Albritton DL, Fehsenfeld FC, Connel PS, Norton RB, Huebert BJ (1983) Atmos Environ 17:1355

8. Forrest J, Tanner RD, Standau D, O'Hario TD, Newman L (1980) Atmos Environ 14:137

9. Loo BW, Jaklevic JM, Goulding FS (1980) In: Liu YA (ed) Fine particles. Academic Press, New York, pp 331-350

10. Saltzman BE (1954) Anal Chem 26:1949

11. Papenbrock T, Stuhl F, Müller KP, Rudolph J (1990) J Atmos Chem (in press) 